\title{
¿Antiguas prácticas? ¿Nuevos escenarios? Entre rumores, verdades y la justicia local en la Subdelegación de Huitzo, 1810 a 1812. Efectos del reformismo borbónico*
}

\author{
Old practices? New scenarios? Between rumors, truths and local justice \\ in the Subdelegation of Huitzo, 1810 to 1812. Effects of Bourbon \\ reformism
}

\author{
Óscar RODRÍGUEZ RoDRÍGUEZ \\ El Colegio de Sonora
}

\begin{abstract}
RESUMEN
El objetivo del artículo es analizar el impacto de la política reformista borbónica en la Nueva España a luz de la Ordenanza de Intendentes de 1786 en la Intendencia de Oaxaca a nivel subdelegacional. El estudio tiene como escenario la disputa jurisdiccional entre el común de la subdelegación de Huitzo y Juan Vicente Vidal, subdelegado; acusado de despojo, estafa, servicios involuntarios y repartimiento forzoso, proceso desarrollado durante el período de 1810 a 1812.
\end{abstract}

\section{PALABRAS CLAVE}

Intendencia; Ordenanza de Intendentes; Repartimiento; Subdelegación; Territorio.

\begin{abstract}
The aim of this article is to analyse the impact of Bourbon reformist policy in New Spain in light of the Ordinance of Intendants of 1786 in the Intendancy of Oaxaca at the subdelegational level. The scenario considered in the study is the jurisdictional dispute between the community of the subdelegation of Huitzo and Juan Vicente Vidal, subdelegate who was accused of looting, fraud, enforced conscription and forcibly implementing repartimientos during the period 1810 to 1812.
\end{abstract}

\section{KEYWORDS}

Intendancy; Ordinance of Intendants; Repartimientos; Subdelegation; Territory.

\footnotetext{
*. El presente forma parte del trabajo en extenso "Prácticas políticas, sociedad y territorio en la subdelegación de Huitzo, Intendencia de Oaxaca, 1786-1825”, auspiciado por el Centro de Estudios Históricos de Región y Frontera de El Colegio de Sonora, México (CEHRF-COLSON). Agradezco las observaciones, precisiones y recomendaciones a una versión preliminar del artículo hechas por los colegas del simposio 47: ¿Intermediarios legales, profesionales, expertos? Actores, saberes y prácticas en la justicia en América, siglos XVIII-XXI reunidos en el marco del XIX Congreso de la Asociación de Historiadores Latinoamericanistas Europeos, "Penser les liens sociaux en Amérique ibérique. Langages, expériences et temporalités (XVI-XXIe siècles)”, celebrado del 23 al 27 de agosto de 2021 en la Université Paris 1 Panthéon-Sorbonne, París. Asimismo, deseo expresar mi agradecimiento a los dictaminadores de la revista Rubrica Contemporanea por sus puntuales observaciones.
} 
A la oficina de José María Lasso corregidor-intendente de la Intendencia de Oaxaca ${ }^{1}$ (véase Mapa 1), llegó una carta fechada el 13 de febrero de 1811 proveniente de la cárcel real de San Pablo, pueblo-cabecera de la subdelegación de Huitzo ${ }^{2}$. En el documento, un grupo de naturales de Santa Cruz, pueblo-sujeto de esa demarcación, denunció que permanecían encarcelados desde agosto de 1810 a causa del repartimiento de maíz que realizó Juan Vicente Vidal, subdelegado de la jurisdicción (véase Mapa $2)^{3}$.

1. La Intendencia de Oaxaca quedó integrada por la Ciudad Capital con la jurisdicción de su corregimiento, sus agregados Atlatlahuca de Oaxaca, Guexolotitlán y 17 subdelegaciones: Cuatro Villas, Chichicapa y Zimatlán, Teutitlán, Ixtepexi, Teposcolula y Tuxtlahuaca, Teutitlán del Camino, Cuicatlán y Papaloticpac, Ixcuintepeque-Peñoles, Teosacualco y Teococuilco, Miahuatlán, Nexapa, Xicayan, Teutitlán del Valle, Mitla y Tlacolula, Yanguitlán y Nochistlán, Xalapa del Estado, Tehuantepeque, Teutitlan y Chinantla, Villa Alta, Huaxuapa y Tonalá. Al final de la época colonial, estaba dividida en un Corregimiento y 21 subdelegaciones (Aurea Commons, El estado de Oaxaca. Sus cambios territoriales, Distrito Federal, Instituto de Geografía de la Universidad Nacional Autónoma de México, 2000, pp. 1921). Para 1793, había una población de 411.334 habitantes, de los cuales el 88\% eran indios, divididos en 936 pueblos. Para 1804, Oaxaca era la cuarta de las 12 intendencias de la Nueva España, con una población de 528860 habitantes; de ellos, 24.400 vivían en la capital y el resto, en más de 900 comunidades del interior (Ronald SPORES, Ñu Ñudzahui. La Mixteca de Oaxaca. La evolución de la cultura Mixteca desde los primeros pueblos preclásicos hasta la Independencia, Oaxaca de Juárez, Pública de Oaxaca, 2018, p. 414).

2. En la documentación histórica es común encontrarse con los topónimos Guaxolotitlán, Guexolotitlán o Guaxilotitlán, Guajolotitlán o Guajilotitlán, Huexolotitlán o Huaxilotitilán, nombres utilizados durante el periodo novohispano, cuando la jurisdicción se regía bajo la figura de Corregimiento. Las variaciones gramáticas son atribuibles a los escribanos, quienes indistintamente los usaron como sinónimos a partir de las variaciones fonéticas de la región. Por último, Guiso, Huiso o Huitzo, derivaciones del término prehispánico Huijazoo. Optamos por Huitzo, tal como se le denomina en la documentación consultada. No omitimos la información previa debido a la confusión que pueda generar en el lector al momento de encontrarse con alguno de los topónimos e inferir que se trate de un lugar distinto. Adquirió el rango de subdelegación en 1787. Se creó a partir del Corregimiento de Guaxilotitlán, situado a "seis leguas llanas” de distancia respecto a la ciudad de Antequera, enclavado en el Valle de Etla, región de los Valles Centrales de Oaxaca (“San Pablo Huitzo, Etla”, en Manuel EsPARZA, Relaciones Geográficas de Oaxaca, 1777-1778, Ciudad de México, Centro de Investigaciones y Estudios Superiores en Antropología Social, 1994, p. 134). La facultad para nombrar subdelegados recayó en el intendente, prerrogativa prevista en el artículo 12 de la Ordenanza de Intendentes. De acuerdo con esa normatividad, los elegidos debían ser españoles, competentes en las causas de guerra, hacienda, justicia y policía, para que "administre justicia en los Pueblos que correspondan al Partido, y mantenga a los naturales en el buen orden, obediencia y civilidad” (Marina Mantilla Trolle, Rafael Diego-Fernández Sotelo y Agustín Moreno Torres, Real Ordenanza para el establecimiento e instrucción de intendentes de exército y provincia en el reino de la Nueva España. Edición anotada de la Audiencia de la Nueva Galicia, edición y estudios, Guadalajara, Universidad de Guadalajara / El Colegio de Michoacán, A. C. / El Colegio de Sonora, 2008, pp. 150-152. El primer subdelegado fue Simón Valdés, nombrado por el intendente Antonio de Mora y Peysal en 1791 en sustitución de Florentín de Carrasco, último alcalde mayor. La cabecera subdelegacional descansó en San Pablo; se componía de Apasco, Mazaltepec, San Juan del Rey, San Lázaro, San Sebastián, Santa Cruz, Suchilquitongo, Tejalápam, Telixtlahuaca, Tlaltenango y Zautla. La población total de la subdelegación era de 5.138 habitantes, un tercio de la proporción correspondiente a la capital (15.704). Su composición étnica se distribuía entre mixtecos y zapotecos; la población de origen español era mínima en la región (José MuRGUía y GALARDí, Memoria estadística de Oaxaca y descripción del Valle del mismo nombre, Veracruz, Secretaría del Patrimonio Nacional, 1821, p. 17).

3 ARCHIVO GENERAL DEL ESTADO DE OAXACA [en adelante, AGEO], Real Intendencia, Subdelegación, Huitzo, exp. 4, leg. 70, f. 1, 1811. 
El repartimiento era un sistema de crédito que involucró a comunidades indígenas y autoridades coloniales ${ }^{4}$. En el escrito añadieron que eran obligados a servir en las casas reales un mayor, un juez y dos topiles "para cuanto se le ofrece" 5 , sin proporcionarles "ni una tortilla para que se mantengan, ni pagarles un medio real para mantener sus familias”6. Tras la lectura de la carta y ante la gravedad de las acusaciones, el intendente turnó el caso al Asesor Ordinario para su valoración.

Mapa 1: Intendencia de Oaxaca

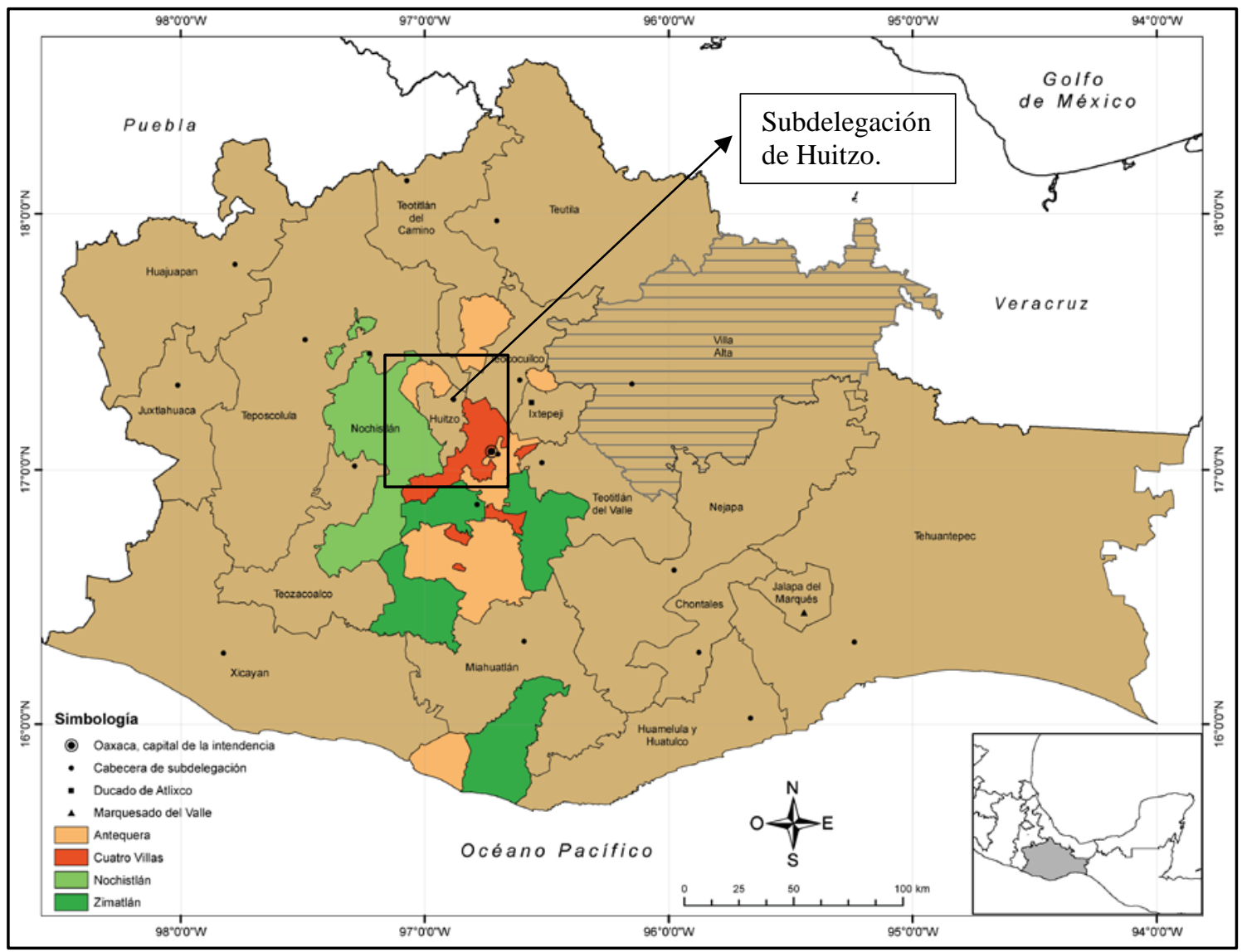

Tomado de Luis Alberto ArRioja DíAz Viruell, "Bernardino María Bonavia y Zapata y el régimen subdelegacional. Relaciones, intereses y funciones”, en Rafael Diego-FERnÁndez SotelO, María Pilar GutiÉRREZ LORENZO y Luis Alberto ARRIOJA DÍAZ VIRUELl (coords.), De reinos y subdelegaciones. Nuevos escenarios para un orden en la América borbónica, Zamora, El Colegio de Michoacán, A.C. I Universidad de Guadalajara / El Colegio Mexiquense, 2014, p. 345.

4. En la provincia de Oaxaca, los alcaldes mayores y corregidores distribuyeron principalmente dinero, aunque en algunos casos maíz, frijol, animales, etc.; el costo del bien adquirido poseía un sobreprecio respecto al valor del mercado. La producción de algodón, mantas y huipiles de Villa Alta y sobre todo la grana cochinilla fueron de las industrias más beneficiadas por el sistema de repartimiento (Jeremy BASKES, Indians, Merchants and Markets. A reinterpretation of the Repartimiento and spanish-indian economic relations in colonial Oaxaca, 1750-1821, Stanford, Stanford University Press, 2000, pp. 2127).

5. AGEO, Real Intendencia, Subdelegación, Huitzo, exp. 4, leg. 70, f. 5, 1811.

6. Ibídem. 
Mapa 2: Subdelegación de Huitzo

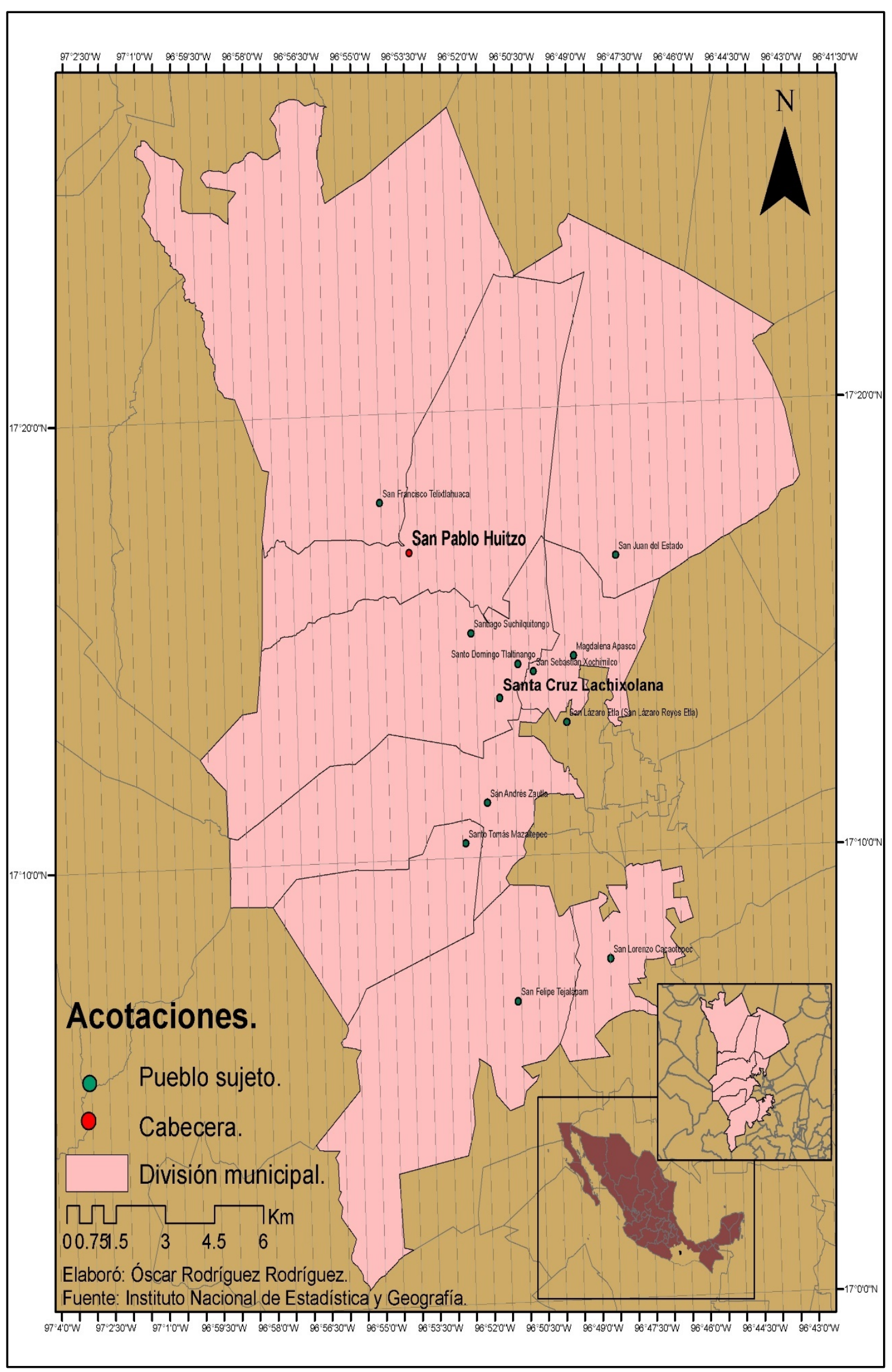


Después de analizar las imputaciones contra Vidal, la denuncia fue admitida el 16 de febrero de ese año. La autoridad libró "oficio proveído" ${ }^{7}$ al subdelegado para el conocimiento de la república y la cabecera y solicitó la presencia de las autoridades de Santa Cruz y San Pablo para interrogarlos acerca de los repartimientos que realizó Juan Vicente $\mathrm{Vidal}^{8}$. El hecho, aparentemente marginal, aislado en el ámbito micro, ofrece pistas para reinterpretar el control jurisdiccional y la complejidad procedimental de la casuística en el plano local. En el ámbito internacional, la época coincide con la crisis de la monarquía española provocada por el asedio francés, hecho que trastocó al virreinato de la Nueva España, doliente al mismo tiempo con el avance insurgente que, para el caso de la Intendencia de Oaxaca significó la toma de la ciudad por los rebeldes encabezados por José María Morelos y Pavón. La convulsión social imperante condicionó la impartición de justicia. La denuncia generó cruces, desencuentros y traslapes jurisdiccionales entre autoridades locales, de la Intendencia y Virreinales debido a la dificultad por dirimir la causa.

Bajo este panorama, el objetivo del artículo es analizar el impacto de la política reformista borbónica en la Nueva España a la luz de la Ordenanza de Intendentes de 1786 en la Intendencia de Oaxaca a nivel subdelegacional, a tenor de la disputa entre el común de la subdelegación de Huitzo y el subdelegado Juan Vicente Vidal, acusado de despojo, estafa, servicios involuntarios y repartimiento forzoso. El proceso fue desahogado durante el periodo de 1810 a 1812. Los actos reclamados contradecían el espíritu de la Ordenanza de Intendentes, cuya vigencia para el tiempo de la acusación era de más de 20 años. El estudio guía la discusión a partir de las preguntas ¿cómo explicar las prácticas denunciadas a la luz de las reformas que las suprimían? Acaso la Ordenanza, que promovía frenar el desaseo de la administración colonial, sanear la hacienda real y eliminar la práctica del repartimiento, ¿fracasó?

La articulación del análisis del caso sigue dos vías. En la primera, nuestra atención se centrará en el repartimiento, y en la segunda, en el contexto sociopolítico en el que se inscribe la denuncia. Valga aquí una aclaración al lector: el presente escrito no entrará al debate de los efectos que tuvo el repartimiento en términos económicos; nuestro interés radica en su uso como instrumento político en las pugnas por el poder y la preservación de prerrogativas. A propósito del complejo entramado en torno al auge y declive del sistema de repartimiento en la Nueva España existe una abundante bibliografía ${ }^{9}$.

\section{AGEO, Real Intendencia, Subdelegación, Huitzo, exp. 4, leg. 70, f. 2 v, 1811.}

8. Las denuncias sobre repartimiento pueden clasificarse en cuatro categorías: primera, los demandantes se quejaban de la disparidad entre los precios del mercado y del repartimiento; segunda, los alcaldes mayores fueron acusados de monopolizar el comercio y bloquear posibles competidores en sus distritos; tercera, los oficiales fueron acusados de usar la violencia para obtener el pago de las deudas, y cuarta, los demandantes acusaron que los repartimientos se hacían mediante coerción (BASKES, Indians, Merchants and Markets... p. 74).

9. Sobre los orígenes del sistema de repartimiento en la Nueva España, véase Rodolfo PASTOR, "El repartimiento de mercancías y los alcaldes mayores novohispanos: un sistema de explotación, de sus orígenes a la crisis de 1810”, en Woodrow BORAH (coord.), El gobierno provincial de la Nueva España, 1570-1787, México DF, Instituto de Investigaciones Históricas de la Universidad Nacional Autónoma de México, 2002, pp. 219-258. En lo que respecta a la introducción y desarrollo del repartimiento en la provincia de Oaxaca durante los siglos XVI al XVIII, véase María Ángeles RoMERo FrIZZI, Economía y vida de los españoles en la Mixteca Alta, 1519-1720, México DF, Instituto Nacional de Antropología e Historia, 1990. Véase también David A. Brading, Mineros y comerciantes en el México borbónico (1763-1810), México DF, Fondo de Cultura Económica, 2015; Brian R. HAMnETT, Política y comercio 
El artículo prioriza la historia local y micro, pues en espacios pequeños se dislocan las jerarquías impuestas, las leyes, los partidos, los Estados ${ }^{10}$, ahí donde la microhistoria es consciente de las inconsistencias de la realidad y de la necesaria parcialidad de nuestro conocimiento ${ }^{11}$. En este nivel, la escala (subdelegacional) es clave para reconstruir de manera sistemática el objeto de investigación ${ }^{12}$. Casualmente, los escalafones más bajos del poder real han sido los menos atendidos por la historiografía, valga la paradoja, ya que son los que proporcionan más respuestas cuando se trata de comprender pueblos, regiones y naciones a la luz del impacto de la Ordenanza de Intendentes, reforma que afectó de manera tan importante a toda Hispanoamérica ${ }^{13}$.

\section{La Ordenanza de Intendentes: subdelegados e intendentes.}

La Real Ordenanza para el Establecimiento e Instrucción de Intendentes de Ejército y Provincia en el Reino de la Nueva España firmada por el rey Carlos III el 4 de diciembre de 1786 (Ordenanza de Intendentes) trajo consigo un reordenamiento del territorio novohispano y la reestructuración del aparato administrativo real. A partir de

en el sur de México, 1750-1821, Oaxaca de Juárez, Universidad Autónoma “Benito Juárez” de Oaxaca / El Colegio de Michoacán, A.C. / El Colegio de San Luis, A.C., 2013. Para adentrarse a las tensiones suscitadas en torno al repartimiento a partir de la implementación de la Real Ordenanza de Intendentes hasta los primeros años de vida independiente en Oaxaca, véase BASKES, Indians, Merchants and Markets; Carlos SÁNCHEZ SILVA, "El comercio indígena en Oaxaca entre colonia y república”, América Latina en la Historia Económica, 12 (1999), pp. 71-84; ídem, Indios, comerciantes y burocracia en la Oaxaca poscolonial, 1786-1860, Oaxaca de Juárez, Instituto Oaxaqueño de las Culturas / Fondo Estatal para la Cultura y las Artes / Universidad Autónoma “Benito Juárez” de Oaxaca, 1998. Dos ejemplos sobre el repartimiento de mercancías al interior de la Intendencia de Oaxaca: Luis Alberto ARRIOJA DíAZ VIRUELL, "De la prohibición a la persistencia: el repartimiento de Mercancías en Villa Alta (Oaxaca)1786-1834”, en Daniela TRAFFANO (coord.), Reconociendo el pasado. Miradas históricas sobre Oaxaca, Oaxaca de Juárez, Centro de Investigaciones y Estudios Superiores en Antropología Social / Instituto de Investigaciones en Humanidades de la Universidad Autónoma "Benito Juárez" de Oaxaca, 2008, pp. 91-129 y Laura MACHUCA, "El impacto del repartimiento de mercancías en la provincia de Tehuantepec durante el siglo XVIII: los pueblos de la grana”, en Margarita MENEGUS (comp.), El Repartimiento forzoso de mercancías en México, Perú y Filipinas, México DF, Instituto Mora / Universidad Nacional Autónoma de México, 2000, pp. 120-145. Recientemente, la revista Temas Americanistas en su número 46 (2021) dedicó un Dossier bajo el título "La vigencia del estudio de los repartimientos en época de subdelegados"; los artículos se centran en la Nueva España, aunque uno de ellos se refiere al Alto Perú.

10. Antonio SANTAMARÍA GARCÍA, "Regiones, subalternos, invisibles, cultura política y desigualdad. Crisis y retorno de lo social en la historia de América Latina en el siglo XX”, Revista de El Colegio de San Luis, 18 (2019), p. 297, https://doi.org/10.21696/rcsl9182019879.

11. Giovanni LEVI, “La microhistoria y la recuperación de la complejidad”, en ídem, Microhistorias, Bogotá, Facultad de Ciencias Sociales de la Universidad de los Andes, 2019, p. 406.

12. Giovanni LEVI, “Un problema de escala”, Relaciones. Estudios de historia y sociedad, 95 (2003), pp. 279, 281, 285. Véase también Georg G. IGGERS, "Desde la macro a la microhistoria: la historia de la vida cotidiana”, en ídem, La historiografía del siglo XX. Desde la objetividad científica al desafío posmoderno, Santiago de Chile, Fondo de Cultura Económica, 2012, p. 171.

13. José Luis AlCAUTER GuZMÁn, Subdelegados y subdelegaciones. Gobierno intermedio y territorio en las intendencias novohispanas, Zamora, El Colegio de Michoacán, A.C., 2017, p. 18. 
esa normatividad se crearon doce intendencias, conformadas por partidos 0 subdelegaciones, surgidas de la extinción de las alcaldías mayores y corregimientos ${ }^{14}$.

La Ordenanza de Intendentes respondía a la necesidad de afrontar el desaseo de la administración colonial y en concreto la práctica del repartimiento. Solía suceder que los alcaldes mayores y corregidores desviaban la recaudación de tributos y otras exacciones para utilizarlo en sus negocios cometiendo fraude al real erario ${ }^{15}$. En el artículo 12 de la Ordenanza se advertía a los subdelegados que no "han de poder repartir a los indios, españoles, mestizos y demás castas, efectos, frutos ni ganados algunos” ${ }^{16}$. Los críticos del repartimiento, incluido José de Gálvez, afirmaban que la exclusión de competidores en los mercados locales controlados por alcaldes mayores y corregidores buscaba aumentar su margen de ganancias al obligar a productores y consumidores indígenas a tratar directamente con ellos ${ }^{17}$. Esa situación contribuyó a la supresión de esos cargos, y mediante la nueva disposición fueron sustituidos por subdelegados ${ }^{18}$. En esa tesitura, los intendentes debían ser capaces de sobreponerse al abuso que por años cometieron las autoridades locales en detrimento de la causa pública (véase Esquema $1)^{19}$.

El estudio del impacto de la Ordenanza de Intendentes en la Nueva España por años se centró en las Intendencias ${ }^{20}$, debido a que las subdelegaciones eran consideradas

14. El proyecto se inspiró en la obra Nuevo sistema de gobierno económico para América, escrita en 1743 por José del Campillo y Cosío, quien fuera secretario de Estado de Felipe V, uno de los primeros y más importantes Intendentes. José de Gálvez en calidad de visitador y con la venía de Carlos III se trasladó a la Nueva España en 1765 para evaluar in situ la viabilidad del proyecto de extender el régimen de intendencias. Gálvez, con el respaldo total del virrey Carlos Francisco de Croix, rápidamente decidió que no solo resultaba conveniente hacerlo, sino un imperante dada la aguda crisis política y social que, según ellos, abrumaba a la principal y más rica joya de la corona en Ultramar: la Nueva España (Rafael DIEGOFERnÁndez Sotelo, El proyecto de José de Gálvez de 1774 en las Ordenanzas de Intendentes de Río de La Plata y Nueva España, Zamora, El Colegio de Michoacán, A.C., 2016, pp. 13-15).

15. Víctor GAYOL, "Retribución de los subdelegados en la Nueva España. Acercamiento preliminar a los derechos de judicatura”, en Rafael DiEGO-FERnÁndez SOTELO, María Pilar GuTiÉRrEz LORENZO y Luis Alberto ARrioja DíAz Viruell (coords.), De reinos y subdelegaciones. Nuevos escenarios para un nuevo orden en la América Borbónica, Zamora, El Colegio de Michoacán, A.C. / El Colegio Mexiquense / Universidad de Guadalajara, 2014, p. 50.

16. Mantilla, Diego-Fernández y Moreno, Real Ordenanza, p. 151.

17. BASKES, Indians, Merchants and Markets, pp. 21-27.

18. Águeda JimÉNEZ PELAYO, “Tradición o modernidad. Los alcaldes mayores y los subdelegados en Nueva España”, Espiral, 21 (2001), p. 148. Véase también Jaime E. RoDRíGUEz O, “’Ningún pueblo es superior a otro’: Oaxaca y el Federalismo mexicano”, en Brian Francis Connaughton Hanley, Poder y legitimidad en México en el siglo XIX: Instituciones y cultura política, Ciudad de México, Universidad Autónoma Metropolitana Unidad Iztapalapa / Miguel Ángel Porrúa, 2003, p. 250.

19. Peter GuARDino, El tiempo de la libertad. La cultura política popular en Oaxaca, 1750-1850, México DF, El Colegio de Michoacán/ El Colegio de San Luis/ Universidad Autónoma "Benito Juárez" de Oaxaca/ Universidad Autónoma Metropolitana-Iztapalapa/ Honorable Congreso del Estado de Oaxaca, 2009, p. 159.

20. La tendencia la podemos identificar en los trabajos de Luis NAVARRo GARCÍA, Intendencias en Indias, Sevilla, CSIC / Escuela de Estudios Hispano-Americanos, 1959, pp. 88-89. Véase también Aurea Commons, Las Intendencias de la Nueva España, México DF, Instituto de Investigaciones Históricas e Instituto de Geografía de la Universidad Nacional Autónoma de México, 1993; Horst PiETschmanN, Las Reformas Borbónicas y el sistema de Intendencias en Nueva España. Un estudio político administrativo, México DF, Fondo de Cultura Económica, 1996. 
“el eslabón más débil dentro de la cadena de mando de la monarquía española” ${ }^{21}$. Se afirmó que su influjo no representó un cambio sustancial en las autoridades, ya que se trataba, supuestamente, solo de una modificación de nombre, pero, las nuevas autoridades seguían siendo los mismos alcaldes mayores y corregidores, supuesto que sugería que tampoco lo hubo de escenarios jurisdiccionales, ya que los cambios al respecto fueron mínimos o de poca trascendencia ${ }^{22}$.

Esquema 1: Estructura jerárquica

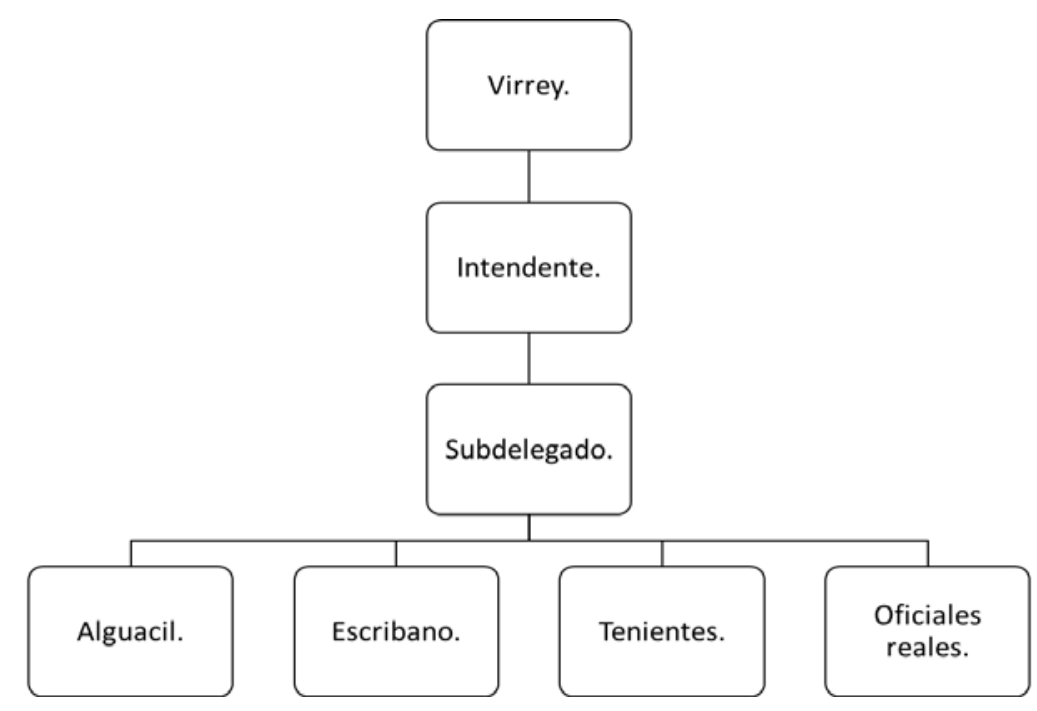

Elaboración propia.

Los subdelegados en particular eran presentados como funcionarios que no cumplían la ley por "perseguir sus intereses económicos" 23 o enfrascarse en conflictos "por el poder en competencia con miembros de la élite local”. De ahí se arguyó que “prácticamente no tuvieron relevancia en el sostenimiento del dominio español”, antes bien "lo perjudicaban". Aunque en la práctica fueron los encargados de instrumentar en el escalafón más bajo de la administración colonial la Ordenanza de Intendentes, convirtiéndose en “mediadores" 24 y/o “intermediarios”25 entre la Intendencia y el

21. José Luis AlCAuter GuZMÁn, "Pueblos de indios novohispanos bajo el régimen de las Subdelegaciones. Un marco normativo”, en Michael T. DUCEY y Luis J. GARCíA RuIz (coords.), De súbditos del rey a ejidatarios posrevolucionarios. Los subalternos en la historia de México: territorio, gobierno, resistencia, Ciudad de México, Universidad Veracruzana / El Colegio de Michoacán, A.C., 2019, p. 52.

22. Rafael Diego-Fernández Sotelo, "Presentación: Consideraciones en torno al concepto de jurisdicción en el Antiguo Régimen”, en ídem, Graciela BERNAL RUIZ y José Luis AlCAUTER GUZMÁN (coords.), Subdelegaciones novohispanas: La jurisdicción como territorio y competencia, Zamora, El Colegio de Michoacán, A.C. / Universidad Autónoma de Zacatecas / Universidad de Guanajuato, 2019, p. 15.

23. Silke HENSEL, "Mediadores del poder: La actuación de los subdelegados y su significado para el dominio español en la Nueva España, 1787-1821”, en Marta TERÁN y Víctor GAYOL, (eds.), La Corona rota. Identidades y representaciones en las Independencias Iberoamericanas, Castellón de la Plana, Publicacions de la Universitat Jaume I, 2010, p. 44.

24. Ibídem, pp. 41-42. 
gobierno de los pueblos. Investigaciones recientes ${ }^{26}$ rebaten la imagen negativa de los subdelegados y documentan la importancia de estudiar la escala territorial de las subdelegaciones debido a que en ella se puede apreciar con "lujo de detalle, la actividad de los grupos de la sociedad, los traslapes jurisdiccionales y el ejercicio cotidiano del gobierno" ${ }^{27}$.

\section{La Intendencia de Oaxaca ¿cambios? ¿continuidades?}

El proceso de implementación de la Ordenanza de Intendentes en la Intendencia de Oaxaca correspondió al corregidor-intendente Antonio Mora y Peysal, que ejerció el cargo de 1787 hasta su muerte en $1808^{28}$. La aplicación de la legislación encontró una férrea oposición en la elite local encabezada por los comerciantes ${ }^{29}$, quienes solicitaron que se dejara sin efecto, específicamente en lo tocante al repartimiento, debido a la importancia que tenía en Oaxaca más que en cualquier otra provincia de la Nueva España $^{30}$.

Mientras se desarrollaban los debates sobre la continuidad o prohibición del repartimiento, los nuevos subdelegados no perdieron el tiempo y siguieron realizándolos como antaño. En Yucatán y Veracruz, por ejemplo, los intendentes recomendaban que se permitiera, debido a que la economía de esas regiones entró en un proceso de declive $^{31}$. En contraste, los de Puebla y Oaxaca mostraron una actitud distinta ${ }^{32}$. El

25. José Luis AlCAUTER GuZMÁn, "Subdelegados y ayuntamientos constitucionales. Momentos gaditanos en Valladolid, 1812-1814, 1820-1822”, en Eduardo Alejandro LÓPEZ SÁNCHEZ y José Luis SOBERANES FERNÁNDEZ (coords.), La Constitución de Cádiz de 1812 y su impacto en el occidente novohispano, Ciudad de México, Instituto de Investigaciones Jurídicas de la Universidad Nacional Autónoma de México, 2015, p. 6.

26. Gracias a la Red de Estudios del Régimen de Subdelegaciones en la América Borbónica (RERSAB) se ha dado un gran impulso por redescubrir el periodo de implementación de la Ordenanza de Intendentes. Esos esfuerzos han culminado con la publicación de dos obras colectivas claves para reinterpretar el periodo: De reinos y subdelegaciones. Nuevos escenarios para un nuevo orden en la América Borbónica, de 2014, y Subdelegaciones novohispanas: La jurisdicción como territorio y competencia, de 2019. Para profundizar en el análisis de las tendencias actuales en el estudio de las subdelegaciones en la América borbónica, véase Lucrecia ENRÍQUEZ, "De las intendencias a las subdelegaciones: dos momentos historiográficos sobre el régimen de intendencias en la América Borbónica”, HiSTOReLo. Revista de Historia Regional y Local, 25 (2020), pp. 182-219, https://doi.org/10.15446/historelo.v12n25.85330.

27. AlCAUter, “Pueblos de indios novohispanos...”, p. 52.

28 María DE JEsús ORDÓÑEZ, “El territorio del estado de Oaxaca: Una revisión histórica”, Boletín del Instituto de Geografía Universidad Nacional Autónoma de México, 42 (2000), p. 75, https://doi.org/10.14350/rig.59115.

29. Los principales promotores fueron:Bernardino Bonavia (influyente comerciante y subdelegado de Villa Alta, una de las subdelegaciones más prosperas de la Intendencia de Oaxaca), Juan Bautista de Echarri, Juan Francisco Echarri, Francisco Antonio Goitia, Manuel Ramón Goya, Juan Carlos Barberena, Antonio Ibañez de Corvera, Vicente Iturribarria y Urquijo. Las presiones que ejercieron llevaron en reiteradas ocasiones al intendente Mora y Peysal a solicitar retirarse del cargo. Sin embargo, esto no fue posible hasta su muerte (Ana Carolina IBARRA, El cabildo catedral de Antequera, Oaxaca y el movimiento insurgente, Zamora, El Colegio de Michoacán, A.C., 2000, p. 103).

30. Los cambios sobre la legalización en 1751 y posterior prohibición del repartimiento en 1786 tuvieron un profundo impacto sobre la economía en la provincia de Oaxaca, específicamente sobre la industria de la cochinilla (BASKES, Indians, Merchants and Markets... pp. 5, 43).

31. JiMÉnEZ PELAYO “Tradición o modernidad...”, p. 148. 
intendente Mora y Peysal (Oaxaca) afirmó que "la eliminación de los repartimientos había liberado a los indígenas de la antigua servidumbre, sin que la agricultura dejara de florecer" ${ }^{33}$. Las posturas del intendente Mora y Peysal a lo largo de su gestión dieron argumentos a sus detractores para acusarlo de ejercer indebidamente su función, por su política "beneficiosa para los indios" ${ }^{34}$. Sin embargo, sus posicionamientos contrastaban con la realidad. Analicemos algunos ejemplos.

En Villa Alta, la subdelegación más próspera de la Intendencia, los subdelegados desafiaron abiertamente a la autoridad. El subdelegado Pablo Ortega (1784-1789) repartió dinero para la producción de algodón, mantas y distribuyó ganado entre los indios. Controló dos tiendas ${ }^{35}$. Bernardo Bonavia, sucesor de Ortega, empleó a un aliado en una tienda que montó en la cabecera de la jurisdicción y desde ahí forzó a "los indígenas a aceptar crédito" 36 ; creía que sin "el repartimiento los indígenas del distrito producirían menos" ${ }^{37}$. Bonavia adelantaba a los indios seis reales por cada carga de algodón que cultivaban, cuando el precio corriente era de 20 reales, distribuía toros y mulas a un costo de 28 pesos, mientras que en el mercado se cotizaban a 14 pesos $^{38}$. Fue acusado de solicitar a los naturales mantas para pagar el tributo. Cuando sus cuentas fueron auditadas en 1799 tenía en su poder cientos de ellas, valuadas en 6.324 pesos $^{39}$.

El intendente Mora y Peysal opinó que los negocios de Bonavia eran “usureros y sin considerar el beneficio de los naturales" 40 . Aseguró que despachaba impositivamente esos tratos al punto de "mantener a los infieles indios [...] en la miseria y opresión, bajo el manto del rey más piadoso y leyes más benignas, y estar sufriendo los efectos de una tiranía" ${ }^{41}$. Las denuncias sobre la conducta del subdelegado fueron apoyadas en su momento por Juan Pío Álvarez, cura de San Ildefonso Villa Alta; según él, mantenía a los indios sumidos en el "despótico y dominante estilo, demasiada soberbia, altanería y majestuoso orgullo que como otro luzbel [...] quiere controlar

32. Una de las primeras medidas que implementó el Intendente Manuel de Flon en la Intendencia de Puebla fue la publicación de un bando donde, entre otras cosas, se recordaba la prohibición de los repartimientos y monopolios y la libertad de que gozaban los indios para comerciar por todo el Virreinato. Las ideas del intendente iban más allá de la supresión de los repartimientos. Para evitar más abusos, Flon creía necesario que se prohibiese la práctica del comercio a los Justicias, curas, administradores de rentas, dependientes de la Acordada y cualquier otra persona que ejerciese cualquier tipo de jurisdicción o comisión pública (Rafael D. GARCíA PÉREZ, Reforma y resistencia. Manuel de Flon y la Intendencia de Puebla, México DF, Editorial Porrúa, 2000, pp. 108-109).

33. JimÉNEZ PELAYO, “Tradición o modernidad...”, p. 149.

34. Silke Hensel, "Los orígenes del federalismo en México. Una perspectiva desde la provincia de Oaxaca de finales del siglo XVIII a la Primera República”, Ibero-amerikanisches Archiv, 3-4 (1999), p. 223.

35. Luis Alberto ARRIOJA DíAz VIRUell, "Bernardino María Bonavia y Zapata y el régimen subdelegacional. Relaciones, intereses y funciones”, en DiEGO-FERnÁNDEZ, GuTIÉRREZ y ARRIOJA, De reinos y subdelegaciones, p. 335.

36. GUARDINO, El tiempo de la libertad, p. 165.

37. Ibídem.

38 ARrioja, “Bernardino María Bonavia y Zapata...”, pp. 336-337.

39. GUARDINO, El tiempo de la libertad, p. 168.

40. ARriojA, “Bernardino María Bonavia y Zapata...”, p. 336.

41. Ibídem, p. 337. 
todo" ${ }^{42}$. En su momento, José Antonio Ortega, administrador de alcabalas en Villa Alta, denunció a Bonavia por la "mala conducta” y el "genio caviloso que despliega contra los súbditos de la Corona” a la vez de cobrar los tributos y repartimientos.

Bernardo Ruiz de Consejares, relevo de Bonavia, llegó al punto que en 1804, tres años después de terminar su gestión, aún le adeudaban 24.624 pesos en 110 pueblos de Villa Alta y tres de Teotitlán del Valle ${ }^{43}$. Para el año de 1808, integrantes de las repúblicas de algunos pueblos de la región levantaron una queja contra el subdelegado Juan Antonio Llaguno, acusándolo de cobrar una cuota por la organización de las elecciones municipales y la entrega de varas de Mando al nuevo titular ${ }^{44}$. A partir de estos ejemplos, es claro que en la Intendencia de Oaxaca los subdelegados lograron obtener grandes ganancias a partir del repartimiento en detrimento de las arcas reales ${ }^{45}$. En la teoría, los nuevos funcionarios serían menos rapaces que los antiguos alcaldes mayores y corregidores; no obstante, los aspirantes para los nuevos puestos provenían del mismo banco de candidatos que las antiguas autoridades ${ }^{46}$.

A la muerte de Mora y Peysal (1808), el principal de sus críticos, José María Izquierdo, tomó interinamente las riendas de la Intendencia. La noticia dio un respiro a sus detractores, que por años impulsaron la derogación de la Ordenanza de Intendentes. Izquierdo ayudó a subdelegados con tropas para cobrar deudas del repartimiento y aceptó dinero para gestionar puestos en la administración ${ }^{47}$. Después del breve interinato llegó el criollo José María Lasso, nombrado intendente por la Junta Suprema Central en Sevilla el 18 de junio de 1809. Entre las primeras acciones que emprendió al tomar el cargo estuvo poner fin al discurso crítico de su antecesor (Mora y Peysal) en torno al repartimiento y aliarse con los comerciantes que por años esperaron que se reestableciera $^{48}$; según ellos, era la única vía para que sobreviviera el comercio de la grana $^{49}$. Favoreció el restablecimiento de un repartimiento reglamentado del tipo que no había podido materializarse según lo dispuesto por la ley que en 1751 intentó reformarlo ${ }^{50}$. Considérese lo siguiente: si el contexto político se tornó más propicio para el repartimiento, ¿por qué la denuncia de los naturales de Santa Cruz contra el subdelegado Juan Vicente Vidal generó un amplio debate?

42. Ibídem.

43. GUARDiNO, El tiempo de la libertad, p. 166.

44. HENSEL, “Mediadores del poder...”, p. 48.

45. Ibídem, p. 43.

46. GuARDINO, El tiempo de la libertad, p. 169.

47. Hensel, “Los orígenes del federalismo en México...”, p. 223.

48. Ana Carolina Ibarra, Clero y política en Oaxaca: Biografía del doctor José de San Martín, México DF, Instituto Oaxaqueño de las Culturas / Universidad Nacional Autónoma de México / Fondo Estatal para la Cultura y las Artes, 1996, p. 66.

49. Ana Carolina IBARRA GonZÁLEZ, “La iglesia en Oaxaca”, en Tomás Federico ARIAS CASTRO, y otros, La constitución de Cádiz y Florencio del Castillo: legado de una época, San José de Costa Rica, Editorial Universidad Estatal a Distancia (EUNED), 2011, p. 176.

50. Brian R. HAmnetT, Revolución y contrarrevolución en México y Perú. Liberales, realistas y separatistas, 1800-1824, México DF, Fondo de Cultura Económica, 2011, p. 171. 


\section{¿Sentencia? La justicia local}

En la comparecencia del 18 de febrero ordenada por el asesor ordinario, las autoridades de Santa Cruz y San Pablo expresaron que "es cierto y que les consta” el repartimiento de maíz que realizó el subdelegado. Apoyaron las declaraciones de los denunciantes. Añadieron en su declaración que Gregorio Gómez, vecino de San Pablo, también fue víctima del funcionario, aunque no precisaron el agravio del que fue objeto. Destacaron que existían más afectados, pero "no saben quiénes sean los individuos en particular" ${ }^{21}$.

En un hecho inusitado, el 26 de febrero de 1811, una semana después de dar curso a la denuncia, el asesor ordinario presentó al intendente José María Lasso un dictamen sobre las acusaciones contra el subdelegado a partir de las indagatorias realizadas al respecto: Determinó que su conducta contravino el artículo 22 de la Ordenanza de Intendentes y la Real Cédula del 27 de julio de $1796^{52}$. La primera legislación vulnerada aludía a la facultad del Intendente para apercibir la "parcialidad, pasión o venganza" de tenientes, subdelegados, alcaldes ordinarios y jueces subalternos en detrimento de la causa pública o los vasallos. En caso de reincidencia debían ser emplazados al Tribunal Superior ${ }^{53}$. La segunda subrayaba la importancia de la observancia del artículo 12 de la Ordenanza de intendentes en lo concerniente a evitar los abusos de los subdelegados en sus jurisdicciones. La resolución se basó en la acusación de los naturales y la información que proporcionaron las autoridades de Santa Cruz y San Pablo. Llama la atención la exclusión del subdelegado durante el desahogo del proceso en esa instancia.

La celeridad para concluir la causa tiene cierto sentido si consideramos el contexto político. Nadie querría una insurrección más de las existentes. La insurgencia poco a poco ganaba terreno. Justo unos meses atrás, Miguel Hidalgo y Costilla encomendó la tarea de sublevar la ciudad de Oaxaca a José María Amienta y Miguel López de Lima. Cuando trataban de entrar a la ciudad fueron descubiertos y fusilados el 31 de diciembre de 1810. Poco tiempo después fue identificada otra, encabezada por José Catarino Palacios y Felipe Tinoco, quienes corrieron con la misma suerte que sus antecesores ${ }^{54}$. Dada la proximidad entre la subdelegación de Huitzo y la capital de la intendencia, lo que afectaba en una repercutía en la otra. Algunos datos dispersos relatan la anécdota sobre la estadía de José María Morelos y Pavón junto al ejército insurgente en San Juan del Rey (pueblo sujeto) en su paso hacia la ciudad. José Antonio Gay refiere que hasta ahí los indios llegaron para entregar "provisiones que fueron muy oportunas" 55 . Lamentablemente, no hay documentación que detalle las actividades de los rebeldes y la reacción de los habitantes de la subdelegación.

51. AGEO, Real Intendencia, Subdelegación, Huitzo, exp. 4, leg. 70, f. 3 v, 1811.

52. AGEO, Real Intendencia, Subdelegación, Huitzo, exp. 4, leg. 70, ff. 5v y 6, 1811.

53. Mantilla, Diego-Fernández y Moreno, Real Ordenanza, pp. 162-163.

54. Juan ORTIZ EsCAMILlA, "Las élites de las capitales novohispanas ante la guerra civil de 1810”, Historia mexicana, 2 (1996), p. 350.

55. José Antonio Gay, Historia de Oaxaca, Prólogo de Pedro VÁsquez Colmenares, México DF, Porrúa, 2006, pp. 615-616. 


\section{Del intendente al virrey, ¿del virrey al intendente? Ámbitos de competencia jurisdiccional}

El 1 de marzo de 1811, el intendente declinó la causa al virrey Francisco Javier Vanegas, de conformidad con las quejas promovidas por el subdelegado Juan Vicente Vidal contra la resolución judicial. La respuesta de Vanegas no tardó en llegar. El 30 de marzo de 1811, la autoridad virreinal se pronunció solo a favor de un "apercibimiento o advertencia” contra el funcionario en atención a la "gravedad de sus excesos". Dejó claro que el apercibimiento surtiría efecto en caso de que "fuere[n] ciertos" los señalamientos acerca de los "repartimientos usurarios de maíz y exacción de servicios personales involuntarios” 56 .

La integración de la causa remitida no estuvo debidamente documentada. En la resolución señala "en el actual estado carece dicho expediente de la instrucción necesaria para poder dictaminarse”. Es comprensible el revés de la justicia real. En el proceso se privilegió la acusación de los naturales sin indagar en los hechos denunciados. En consecuencia, el expediente fue devuelto al intendente. El virrey instó a las autoridades a formar una comisión que investigara las acusaciones, especificando "los sujetos y las cantidades que haya repartido entre ellos”. Ordenó al subdelegado no "cobrar cantidad alguna de los expresados repartimientos", poner en libertad a los deudores y no solicitar servicio personal "hasta la definitiva resolución”. A partir de las diligencias efectuadas por la comisión que se formó, se sumaron dos víctimas: Juan María Caballero y Bernarda González, naturales de San Pablo. Acusaron al subdelegado de estafarlos con una cosecha de maíz y frijol que acordaron sembrar juntos; Bernarda añadió que también la despojó de tierras y trigo ${ }^{57}$.

Abro aquí un paréntesis para poner sobre la mesa algunas consideraciones. La llegada de Juan Vicente Vidal a la subdelegación de Huitzo se vio inmersa entre la "voluntad del pueblo" y la disposición real. En la sucesión para ocupar el cargo de subdelegado correspondiente al año 1810, puesto que dejaba vacante José Romero Ayala (1809), se presentaron dos escenarios:

1. El 16 de junio de 1810, las autoridades de la subdelegación (véase Tabla I) dirigieron un oficio a Francisco Villasana, intendente interino; le externaron estar al tanto que Francisco de Llaguno fue nombrado subdelegado de Nochixtlán para el año de 1810. Él sirvió a la jurisdicción de Huitzo intermitentemente por el lapso de doce años. De acuerdo con la información que tenían, se encontraba en disposición de renunciar a la designación. Al encontrarse vacante la de Huitzo, lo recomendaron. Su petición se basó en que de él solo "recibieron continuados beneficios sin que jamás tuvieren el más mínimo motivo de queja en ningún tribunal”58. Para robustecer la recomendación, Francisco de Llaguno, solicitó el 30 de junio de ese año al teniente letrado Antonio María Izquierdo certificara su “conducta y manejo" ${ }^{59}$ de la subdelegación de Huitzo.

2. A pesar de los exhortos, se designó a Juan Vicente Vidal, quien se mantuvo en el cargo de 1810 a 1812.

56. AGEO, Real Intendencia, Subdelegación, Huitzo, exp. 4, leg. 70, ff. 6-6v, 8, 9, 10, 22 y 22v, 1811.

57. AGEO, Real Intendencia, Subdelegación, Huitzo, exp. 4, leg. 70, 8, 9, 10, 22 y 22v, 1811.

58. ARCHIVO HISTÓRICO DE LA DIRECCIÓN GENERAL DE NOTARIAS DE OAXACA (en adelante: AHDGNEO), Escribano Joseph Álvarez, nº de libro 84, f. 146v, 1810.

59. ARCHIVO HISTÓRICO MUNICIPAL DE LA CIUDAD DE OAXACA (en adelante: AHMCO), Actas de cabildo, Sesiones ordinarias, Libro 4, f. 85v, 1810. 
RODRÍGUEZ

Tabla 1: Subdelegación de Huitzo, 1810. Autoridades que recomendaron a Francisco de Llaguno $^{60}$

PUEBLO

San Pablo Huitzo
AUTORIDAD

Alcaldes: Martin Abendaño, Ysidro López.

Regidores: José García, Justo de la Cruz, Manuel Paz, Bernardo Hernández.

Escribano de república: Bartolomé Gómez. Alcalde: Bernardo Cruz.

Regidores: Domingo Sánchez, Agustín López, Antonio Ramírez, Martín Trujillo.

Escribano de república: Rafel Escámela.

\begin{tabular}{l|l}
\hline Santiago & Alcalde: Manuel Baptista.
\end{tabular}

Regidores: Mauricio Vásquez, Francisco Velasco, Miguel Martin. Escribano de república: Basilio de San Pedro.

\begin{tabular}{l|l}
\hline San Lázaro & $\begin{array}{l}\text { Regidores: Raymundo Mendoza, Joaquín Mendoza. } \\
\text { Escribano de república: Juan de Dios Mendoza. }\end{array}$ \\
\hline San Sebastián & $\begin{array}{l}\text { Alcalde: Felipe Hernández. } \\
\text { Regidores: Juan Esteban Méndez. } \\
\text { Escribano de república: Antonio Cruz. }\end{array}$ \\
\hline Santa Cruz & $\begin{array}{l}\text { Alcalde: Lucas López. } \\
\text { Regidores: Pascual García. } \\
\text { Escribano de república: Rafael García. }\end{array}$ \\
\hline San Andrés Zautla & $\begin{array}{l}\text { Alcaldes: Juan de Sosa, Gregorio Hernández. } \\
\text { Regidores: Pedro López, Manuel Pérez. } \\
\text { Escribano de república: Manuel Reyes. }\end{array}$ \\
\hline Santo Thomas Mazaltepec & $\begin{array}{l}\text { Alcaldes: Bonifacio García, Nicolas Cruz. } \\
\text { Regidores: José Cruz, Pedro López. } \\
\text { Escribano de república: Vicente Pérez. }\end{array}$ \\
\hline Magdalena & $\begin{array}{l}\text { Alcalde: Rafael Pérez. } \\
\text { Regidores: Francisco Mexía, Manuel Ojeda. } \\
\text { Escribano de república: Pedro González. }\end{array}$ \\
\hline Santo Domingo & $\begin{array}{l}\text { Alcalde: Manuel García. } \\
\text { Regidores: Feliciano Villanueva, Francisco Sosa. }\end{array}$ \\
\hline San Juan del Rey & $\begin{array}{l}\text { Alcalde: Juan Ruiz. } \\
\text { Regidores: Feliciano López, Luis Pérez. } \\
\text { Escribano de república: Pedro Anastasio Díaz. }\end{array}$ \\
\hline San Lorenzo & $\begin{array}{l}\text { Alcaldes: Mathias Muñoz, Manuel Reyes. } \\
\text { Regidores: Francisco Muñoz, Toribio Santiago. } \\
\text { Escribano de república: Simón Vasquez. }\end{array}$ \\
\hline $\begin{array}{l}\text { Alcaldes: Jacinto Espinoza, Vicente López. } \\
\text { Regidores: Mathias López, Esteban Santiago. } \\
\text { Escribano de república: Victoriano Méndez. }\end{array}$ \\
\hline
\end{tabular}

60. AHDGNEO, Escribano Joseph Álvarez, nº de libro 84, f. 145v, 1810. 
Acaso esta serie de denuncias provenían de la inconformidad del pueblo con la elección del subdelegado ¿Repartió, estafó y despojó, como constaba en la querella? ¿Quién era Francisco de Llaguno? ¿Cuál era el propósito para que el antiguo subdelegado se reinstalara en el cargo? ¿Cuál era la relación de los pueblos con ese personaje?

\section{¿El recomendado?}

Francisco de Llaguno, de origen español, fue un comerciante con residencia en la ciudad de Oaxaca. Entre sus propiedades contó con La Hermosa ${ }^{61}$, un molino, Cinco señores $^{62}$, una hacienda de labor de molino y una casa en la capital de la Intendencia valuada en 4.000 pesos $^{63}$. Con base en la información disponible sobre la familia Llaguno, podemos hacer los siguientes comentarios. En 1796, año en el que recibió la jurisdicción de Huitzo ${ }^{64}$, su sobrino Juan Antonio Llaguno fue nombrado subdelegado en Nexapa, cargo que también ejerció para el periodo de 1802 a 1810 en la subdelegación de Villa Alta, la más rica de la Intendencia. Joaquín, hijo de Francisco, resultó ser juez de primera instancia en el Distrito de Teposcolula después de la Independencia ${ }^{65}$.

Gracias a las buenas relaciones que mantenía con otros miembros de la elite local, para su primer período como subdelegado (1796) nombró como sus fiadores a Joseph Regules, Francisco de la Torre Marroquín, Vicente Villaverde y Juana Cortabarría. Se desempeñó en el cargo durante los años 1796, 1797, 1799, 1800, 1801, 1805, 1806 y 1807. Al concluir su gestión, se trasladó a la subdelegación de Nochistlán ubicada en la Mixteca Alta; ahí prestó su servicio en 1808, 1809, 1810, 1811, 1814, 1815 y 1816. Para su cuarto año como subdelegado de Nochistlán, designó fiador a José Solaegui, prominente comerciante de aquella región por la cantidad de 2.000 pesos $^{66}$.

En compañía de Antonio Moreda, subdelegado de Zimatlán, se constituyeron fiadores de Pedro Lezaeta y Joseph Estrada administradores provistos de la Renta de Tabaco, Pólvora, Naipes y Papel Sellado por la cantidad de 2.000 pesos. Durante su mandato en Huitzo (1801) solicitó un préstamo por 12.000 pesos, se comprometió a pagarlo en un plazo de 9 años. En garantía, hipotecó el molino Cinco señores. Saldó la deuda durante su gestión como subdelegado de Nochistlán (1814). Al poco tiempo se lo vendió a Gabriel de Felgueres en 42.000 pesos. En la documentación consultada no fue

61. AHDGNEO, escribano Pedro Auvray, no de libro 136, f. 157, 1794.

62. AHDGNEO, escribano Joseph Álvarez, nº de libro 75, f. 36v, 1801.

63. Silke Hensel, “Subdelegados de la Intendencia de Oaxaca, 1787-1820. Estudio prosopográfico”, en DiEgo-FERnÁNDEZ, GUTIÉRREZ y ARRIOJA, De reinos y subdelegaciones, p. 298.

64. AHDGNEO, escribano Joseph Álvarez, nº de libro 75, f. 55v, 1796.

65. HENSEL, “Subdelegados de la Intendencia de Oaxaca...”, p. 298.

66. AHDGNEO, escribano Joseph Álvarez, núms. de libro 75, ff. 36v y 55v, 1796; 72, f. 53v, 1797; 73, f. 180v, 1799; 79, f. 26v, 1805; 80, f. 117, 1806; 79, f. 26v, 1805; 82, f. 226, 1808; 83, f. 57, 1809; 84, f. 63, 1810; 85, ff. 180 y 181v, 1811; 87, f. 77, 1814; 88, f. 54v, 1815, y 89, f. 119v, 1816. AGEO, Real Intendencia, Subdelegación, Huitzo, exp. 10, leg. 69, fs. 1, 1800. 
posible identificar algún vínculo especifico que no sea de índole política con los pueblos de Huitzo. Ello no excluye los tratos hechos al margen de la ley ${ }^{67}$.

\section{¿El acusado?}

Juan Vicente Vidal compareció ante la autoridad el 11 de septiembre de 1812 consecuente al decreto del virrey Francisco Javier Vanegas con fecha del 2 de abril de 1811. Afirmó que en respuesta a la carestía de maíz abasteció la demanda a petición de Joseph Romero, cura de la cabecera, y se comprometió a satisfacer "otras necesidades" de la jurisdicción ${ }^{68}$. En esos años la región de los Valles Centrales atravesó una crisis de granos $^{69}$. Del maíz que distribuyó a la fecha de su comparecencia aún le adeudaban 150 pesos. Señaló al sacerdote como testigo de sus afirmaciones. Precisó que al solicitarles el pago respectivo, los naturales se negaron a realizarlo y a partir de entonces lo llamaron "trato usurario"; con relación a los servicios involuntarios, en la causa asentó “a mí no me sirven” cuando requería ayuda les pagaba “dos reales”, según él "nunca los e [sic] obligado a que me trabajen de valde" ${ }^{70}$.

No es de sorprender que esas demandas enmascararan truculentas formas de evadir el pago que correspondía al bien recibido. En muchos casos se ha subestimado la capacidad de acción-reacción de los indígenas que, conscientes de la legislación, sabían que acusar al subdelegado de coerción les daría un argumento infalible frente a los supuestos abusos a los que eran sometidos ${ }^{71}$. El subdelegado negó que el motivo del encarcelamiento de los naturales de Santa Cruz fuera producto del supuesto repartimiento que realizó. Aseveró que llegaron ahí tras dos denuncias, la primera, interpuesta por José Mariano Torres, de la Villa de Etla, quien manifestó que tenían una deuda con él, les sugirió que, si no le pagaban, al menos "se fueran a desquitar con el trabajo personal respecto a aberles [sic] dado el dinero con este fin"72; se negaron. La segunda fue la contraída con el cura Joseph Romero por las ofrendas que le debían ${ }^{73}$. Como arbitrio de la justicia, explicó: "me era indispensable valerme del remedio de que pagasen o aprisionarlos"74. Jeremy Baskes analizó una serie de denuncias por repartimiento forzoso radicadas en Oaxaca correspondientes al periodo 1750 a 1821. Llama la atención que solo encontró 5 acusaciones, de las cuales afirma "hay duda de la veracidad de varias de ellas"75. En suma, si el repartimiento fue coercitivo como se afirmó, la incidencia hubiese sido mayor. Las acusaciones salían a relucir, después de solicitar el pago y el deudor se declaraba insolvente para realizarlo ${ }^{76}$.

67. AHDGNEO, escribano Joseph Álvarez, núms. de libro 73, f. 180v, 1799; 75, f. 36v, 1801, y 87, f. 77, 1814.

68. AGEO, Real Intendencia, Subdelegación, Huitzo, exp. 4, leg. 70, f. 64 v, 1811.

69. AHMCO, Actas de cabildo, Sesiones ordinarias, Libro 4, f. 82, 1810.

70. AGEO, Real Intendencia, Subdelegación, Huitzo, exp. 4, leg. 70, ff. 64 y 69, 1811.

71. GuARDino, El tiempo de la libertad, p. 165.

72. AGEO, Real Intendencia, Subdelegación, Huitzo, exp. 4, leg. 70, f. 65, 1811.

73. Íbídem.

74. AGEO, Real Intendencia, Subdelegación, Huitzo, exp. 4, leg. 70, f. 68, 1811.

75. BASKES, Indians, Merchants and Markets, p. 83.

76. Ibídem, p. 79. 
El subdelegado reconoció que compró maíz para venderlo con "un corto lucro”, recalcó: "para sostenerme y mantener a mi familia"77. Subrayó que el empleo de subdelegado "en la estinción de los tributos no me daba cosa alguna”. Aclaró que en la jurisdicción nadie diría que repartió "dinero para grana ni mula, ni toros a esesivos”, lo que "verdaderamente esta proibido [sic]" ${ }^{78}$. Pongamos lo anterior en perspectiva. El salario de un subdelegado correspondía al 5\% del total de los tributos recaudados, pero para 1810, de las 18 subdelegaciones que componían la intendencia de Oaxaca, solo del 5\% Villa Alta obtenía 2.383 pesos, Teposcolula 826, Huajuapan 682, Tehuantepec 497, Teutila 470 y Teotitlán 400, pero de ahí afuera todas tenían rentas inferiores a 400 pesos, algunas incluso tan bajas como los 54 pesos de Huamelula, los 120 de Huitzo o los 138 de Chontales ${ }^{79}$. La historiografía situó por años la falta de ingresos dignos como la causa principal del fracaso de la Ordenanza de Intendentes debido a los graves problemas que acarreó ${ }^{80}$.

Respecto a las denuncias de Bernarda González y Juan María Caballero, en ambos casos el funcionario reconoció los tratos. Comentó que la primera omitió mencionar el préstamo que le hizo, al cumplirse el plazo para cubrir la deuda y no tener los recursos para solventarla, le sugirió que "cojiera un pedazo de tierra de temporal para sembrarlo", aunque eso no cubría las "veinte y tantas fanegas" que aún le adeudaba $^{81}$. Juan María faltó al convenio, no entregó la cosecha pactada y para evadir la deuda, el denunciante se valió de "vulnerar mi onor [sic] con suponerme usurero". De acuerdo con los argumentos de Juan Vicente Vidal, los "beneficiaba”: aumentó la agricultura, los diezmos y reales alcabalas, datos que, según el indiciado, el colector de diezmos de Huitzo y del Valle de Etla corroborarían. Debido a los constantes conflictos en los que estaba inmiscuido, el subdelegado solicitó al virrey no le comisionase más en esta clase de diligencias debido a que solo le traían enemigos ${ }^{82}$.

\section{Los acusadores, el indiciado y la autoridad local}

Tras conocer las declaraciones del subdelegado, las autoridades de los pueblos de la subdelegación de Huitzo dirigieron una carta al asesor ordinario de la Intendencia el 24 de septiembre de 1812 (véase Tabla 2). En la misiva le solicitaron que evitara el reintegro de Juan Vicente Vidal a sus funciones, bajo el argumento de haberlo “capitulado de un mal juez que vendía la justicia” para indultar "delincuentes" ${ }^{83}$. A pesar de sus exhortos, volvió.

Después de desechar la moción de las autoridades, el 29 de septiembre de 1812 el escribano ordinario de la Intendencia hizo de conocimiento público el veredicto en torno a las acusaciones contra el subdelegado. Concluyó que las acusaciones carecían de

77. AGEO, Real Intendencia, Subdelegación, Huitzo, exp. 4, leg. 70, fs. 64 v - 65, 1811.

78. AGEO, Real Intendencia, Subdelegación, Huitzo, exp. 4, leg. 70, f. 66, 1811.

79. Laura MACHUCA GALLEgos, “Súplicas al rey por parte de los aspirantes a subdelegados de Yucatán, 1796-1818”, Relaciones. Estudios de Historia y Sociedad, 158 (2019), p. 99. https://doi.org/10.24901/rehs.v40i158.359.

80. GAYOL, “Retribución de los subdelegados en la Nueva España...”, p. 50.

81. AGEO, Real Intendencia, Subdelegación, Huitzo, exp. 4, leg. 70, ff. 65 v - 66, 67 y 68v, 1811.

82. ARCHIVO GENERAL DE LA NACIÓN, Ramo de tierras, vol. 1.411, exp. 3, f. 18, 1811.

83. AGEO, Real Intendencia, Subdelegación, Huitzo, exp. 4, leg. 70, fs. 70- 70 v y 71, 1811. 
fundamento, observó que los tratos denunciados eran permitidos en el artículo 12 de la Real Ordenanza de Intendentes, registró en el expediente "no contienen el más mínimo uso de usura ni lo que se dice sobre servicios personales y exacciones indebidas" y enfatizó "es nada cierto". En consecuencia, las afirmaciones de los testigos eran "de ningún valor ni efecto” (véase Tabla 3) ${ }^{84}$.

Tabla 2: Subdelegación de Huitzo, 1812. Comisión de pueblos para evitar el reingreso del subdelegado

\begin{tabular}{l|l|l}
\multicolumn{1}{c|}{ NOMBRE } & CARGO & \multicolumn{1}{c}{ PUEBLO } \\
\hline Mariano de Castillejos & Alcalde & Republica de la cabecera de Huitzo \\
Leandro de la Cruz & Alcalde & San Francisco \\
Marcelino Herrera & Alcalde & San Andrés Zautla \\
Manuel Cruz & Escribano & Santo Tomás \\
Nazario de la Cruz & Escribano & San Felipe \\
Manuel Méndez & Escribano & San Lorenzo \\
Francisco Chávez & Escribano & San Lázaro \\
José de los Santos & Escribano & Magdalena \\
Vicente Hernández & Escribano & San Sebastián \\
Joseph García & Escribano & Santo Domingo \\
Mariano García & Escribano & Santa Cruz
\end{tabular}

Tabla 3: Relación de las acusaciones

FECHA DEL ILÍCITO ACTOS RECLAMADOS

\begin{tabular}{l|lll} 
PUEBLO & ACUSADORES & FECHA DEL ILÍCITO & ACTOS RECLAMADOS \\
\hline \multirow{5}{*}{ Santa Cruz } & $\begin{array}{l}\text { Antonio de los } \\
\text { Santos }\end{array}$ & & \\
& $\begin{array}{l}\text { Juan García } \\
\text { Agustín Morales } \\
\text { Bernardo Morales } \\
\text { Mariano Morales }\end{array}$ & Ag.1810 & $\begin{array}{l}\text { Repartimiento (maíz) } \\
\text { Servicios involuntarios } \\
\text { (mayor, juez y dos topiles) }\end{array}$ \\
\hline \multirow{5}{*}{ San Pablo } & Gregorio Gómez & Sin fecha & No se precisó el ilícito \\
\cline { 2 - 5 } & Juan María Caballero & Oct. de 1810 & Estafa (sembradío de frijol) \\
\cline { 2 - 5 } & Bernarda González & 1810 (sin fecha exacta) & $\begin{array}{l}\text { Estafa (sembradío de maíz), } \\
\text { despojo de trigo y tierras }\end{array}$
\end{tabular}

El 11 de noviembre de 1812, Juan Vicente Vidal se pronunció sobre la resolución. Identificó que las invenciones de los naturales fueron instigadas por el antiguo subdelegado Francisco de Llaguno, "por cuyos influjos han promovido los indios estos injustos capítulos" Las confabulaciones se hicieron, según Vidal, "tan solo por el interés de [...] volver a aquella jurisdicción”, donde Llaguno "tiene el mayor giro de sus intereses", los que "efectivamente si son, quando no usurarios, bastantemente ventajosos" ${ }^{85}$.

En el fondo de la denuncia se encontraba la posibilidad de reingreso de un funcionario que se benefició del repartimiento. Desconocemos si se dio seguimiento a las acusaciones de Juan Vicente Vidal o si se apercibió a las autoridades de la jurisdicción. Como dice el dicho, en política no hay coincidencias. La resolución del

84. AGEO, Real Intendencia, Subdelegación, Huitzo, exp. 4, leg. 70, f. 73 v, 1811.

85 AGEO, Real Intendencia, Subdelegación, Huitzo, exp. 4, leg. 70, f. 74, 1811. 
caso coincide con la toma de la ciudad de Oaxaca por José María Morelos y Pavón. En esa época, en España se promulgaba la Constitución de Cádiz, la cual no llegó a proclamarse en Oaxaca ese año, sino hasta 1814, después de la ocupación insurgente, ero, solo estuvo vigente unos pocos meses debido a la vuelta al poder de Fernando VII, quien en mayo de ese mismo año la abolió para instaurarse como monarca absoluto ${ }^{86}$.

\section{Conclusiones}

Decía el arzobispo Lizana y Beaumont que la calumnia era un vicio dominante en la Nueva España. Tanto la elite como el común recurrieron a ella. Junto a la intriga y la difamación, fueron armas de las que se valieron las autoridades de la Subdelegación de Huitzo para pretender destituir al subdelegado Juan Vicente Vidal y reinstalar a Francisco de Llaguno, símbolo de las prácticas que tanto habían aquejado a la Real Hacienda ¿Por qué era tan codiciado el territorio de Huitzo? Primero, gozó de agua y tierra suficiente para el cultivo; segundo, su posición era estratégica al conectar a la Mixteca con los Valles Centrales de Oaxaca. La disputa por el control de la Subdelegación en el fondo estaba en línea con las grandes discusiones sobre el restablecimiento del repartimiento en la intendencia. Las elites, no solo comerciales, sino también eclesiásticas y políticas, hicieron lo imposible para que eso sucediera. El momento era el correcto por la inestabilidad imperante en la administración colonial. Volvamos a la pregunta inicial, ¿acaso la Ordenanza que promovía frenar el desaseo de la administración colonial, sanear la hacienda real y eliminar la práctica del repartimiento fracasó?

Es cierto que con tan corta evidencia no podemos plantear un panorama general en torno al éxito o fracaso de la Ordenanza de Intendentes en Oaxaca. Sin embargo, sí podemos tomar el pulso al desenvolvimiento institucional que tuvo. El ejemplo que aquí nos convocó, desde múltiples aristas nos mostró las desavenencias de un funcionario local frente al ejercicio de sus funciones, problemática a las que se suma la falta de un salario digno, al que prácticamente se le atribuyó el fracaso de la reforma. El proceso es claro sobre la dificultad de la administración colonial para hacer valer su jurisdicción. Las ideas ilustradas que llegaron de la mano con la Ordenanza no tuvieron el éxito que esperaban. Se toparon con una sociedad y un aparato de gobierno anquilosado en el Antiguo Régimen. Aproximarnos al contexto histórico de la querella contra Juan Vicente Vidal es encontramos con una escasa documentación. Sin embargo, la existente para el análisis del caso es rica en detalles, de ahí la valía de nuestro trabajo. Sin una mirada crítica a una escala local, nuestro ejercicio no hubiera desentrañado las complejas relaciones que se dan al interior de los pueblos.

Hemos caído en la falacia de hacer tabla rasa del pasado a partir de los grandes acontecimientos suscitados en las capitales provinciales o ciudades principales; damos por sentado que fuera de ahí no hay historia, sino un cúmulo de anécdotas. Ciertamente, el éxito o fracaso de la Ordenanza de Intendentes solo será perceptible en la medida en la que nuestras investigaciones desciendan a una escala micro y nos den luz sobre la recepción y desenvolvimiento al interior de los pueblos.

86. Huemac EsCALONA LÜTTIG, “Manipulación política y conflicto interno. La presencia insurgente en la zona Mixe Baja de Oaxaca, México, 1812-1818”, Anuario de Estudios Americanos, 1 (2013), pp. 162163, https://doi.org/10.3989/aeamer.2013.1.06. 